\title{
CUSTODIA COMPARTIDA Y VIOLENCIA DE GÉNERO: CUESTIONES CONTROVERTIDAS EX ART. 92.7 C. CIVIL ${ }^{1}$
}

\author{
Ana María Pérez Vallejo ${ }^{2}$
}

\begin{abstract}
Custodia compartida y violencia de género: cuestiones controvertidas ex art. 92.7 C. Civil
Resumen: Ante episodios de violencia doméstica o violencia de género es cuestión controvertida si debe o no adoptarse o, en su caso, mantener el régimen de guarda y custodia compartida. El art. 92.7 del Código civil con una redacción imprecisa lo prohíbe expresamente, pero muchas resoluciones judiciales matizan el rigor de la norma y establecen la custodia conjunta. Otras, más allá de la norma, ordenan la suspensión del "derecho de visitas" en línea con las previsiones establecidas en las Leyes 8/2015 y 26/2015 de modificación del sistema de protección a la infancia y a la adolescencia. El presente estudio analiza algunas cuestiones controvertidas que plantea la aplicación práctica del vigente art. 92.7 C.c. conectándolo con el art. 95 bis 5 del Anteproyecto de Ley de Responsabilidad Parental, que introduce importantes modificaciones, unas acertadas y
\end{abstract} otras no exentas de algún reparo.

Palabras clave: custodia compartida, violencia de género, menores.

Shared Custody and Gender Violence: Controversies posed by Article 92.7 of the Spanish Civil Code

Abstract: In the face of domestic violence or gender violence, it is a controversial issue whether or not to adopt or, where appropriate, maintain the shared custody and custody regime. The art. 92.7 of the Civil Code with an imprecise wording expressly prohibits it, but many court rulings tint the rigor of the rule and establish joint custody. Others beyond the norm, order the suspension of the "right of visits" in line with the provisions established in Laws 8/2015 and 26/2015 to modify the system of protection of children and adolescents. The present study analyzes some controversial questions posed by the practical application of the current art. 92.7 C.c. Connecting it with art. 95 bis 5 of the Preliminary Draft Law on Parental Responsibility, which introduces important modifications, some correct and others not exempt from some repair.

Key word: shared custody, gender violence, children.

\section{Interés del menor y custodia compartida}

1.1. De la "excepcionalidad" del Código civil a la "normalidad" en la jurisprudencia del Tribunal Supremo

\footnotetext{
${ }^{1}$ Fecha de recepción: 03/10/2016.

Fecha de aceptación: 21/11/2016.

${ }^{2}$ Profesora Titular de Derecho Civil, Departamento de Derecho, Universidad de Almería; $\square$ amperez@ual.es. Este trabajo se realiza en ejecución del Proyecto I+D+I del Programa Estatal de Investigación, Desarrollo e Innovación Orientada a los Retos de la Sociedad: "Análisis jurídico y cuantitativo de la violencia en la infancia y adolescencia: propuestas de intervención socio-legal" (DER2014-58084-R). IP: Ana M Pérez Vallejo.
} 
El régimen de guarda y custodia de los hijos e hijas tras la ruptura de la convivencia responde al cumplimiento de la protección social y jurídica de la familia; y en particular, a la protección integral del menor (art. 39.2, 3 y 4 CE). En esta materia, el Código civil sigue el modelo de custodia exclusiva preferente y la custodia conjunta como excepcional. Así, el art. 92 C.c. determina que podrá acordarse siempre en interés del menor, cuando sea pedida por ambos progenitores (apartado 5); y "excepcionalmente", a instancia de una de las partes, con informe "favorable" ${ }^{3}$ del Ministerio Fiscal; fundamentándola en que sólo de esta forma se protege adecuadamente el interés superior del menor (apartado 8).

No obstante, el Tribunal Supremo ha matizado la interpretación de la norma y actualmente configura la custodia compartida como el sistema "normal e incluso deseable", 4 por los beneficios que reporta esta modalidad de ejercicio de la responsabilidad parental. Línea de pensamiento reivindicada desde muchos sectores y que el TS refrenda, ${ }^{5}$ al ser pacífico admitir que este modelo de reparto de la convivencia, fomenta y facilita a los hijos e hijas una equitativa comunicación e integración con ambos progenitores; evita desequilibrios en los tiempos de presencia; no existe sentimiento de pérdida; no se cuestiona la idoneidad de los progenitores y promueve la cooperación y coparentalidad en beneficio del menor. Lo que se pretende con esta medida, es asegurar el adecuado desarrollo evolutivo, estabilidad emocional y formación integral del menor. En definitiva, "aproximarlo al modelo de convivencia existente antes de la ruptura matrimonial y garantizar al tiempo a sus padres la posibilidad de seguir ejerciendo los derechos y obligaciones inherentes a la responsabilidad parental; así como participar en

\footnotetext{
${ }^{3}$ En este punto debe recordarse que el inciso "favorable" contenido en el apartado $8 .^{\circ}$ del art. 92 del Código civil, según redacción dada por la Ley 15/2005, de 8 de julio, fue declarado inconstitucional y nulo por Sentencia del Tribunal Constitucional (Pleno) de 17 de octubre de 2012, por ser contrario a los arts. 117, $24.1,14$ y 39 CE.

${ }^{4}$ Vid. por todas la STS núm. 194/2016, de 29 de marzo (Id Cendoj: 28079110012016100182). Esta sentencia de modo contundente hace una llamada de atención a la Audiencia Provincial de Madrid por no haber concedido la custodia compartida. Dice el TS que "La sentencia no solo desconoce la jurisprudencia de esta Sala sobre la guarda y custodia compartida, sino que más allá de lo que recoge la normativa nacional e internacional sobre el interés del menor, resuelve el caso sin una referencia concreta a éste, manteniendo la guarda exclusiva de la madre y dejando vacío de contenido el art. 92 C.c. (...).

${ }^{5}$ Vid. STS núm. 96/2015, de 16 de febrero. Ponente: Arroyo Fiestas.
} 
igualdad de condiciones en el desarrollo y crecimiento de sus hijos, lo que sin duda parece también lo más beneficioso para ellos". ${ }^{6}$ Por lo que ya existe una línea jurisprudencial consolidada que apuesta por su otorgamiento preferente, salvo casos excepcionales, "siempre que ello sea posible y en tanto en cuanto lo sea". ${ }^{7}$ Incluso aunque existan malas relaciones post-ruptura, ${ }^{8}$ sin perjuicio de que, a nuestro modo de ver, sí será imprescindible que entre el padre y la madre exista una relación de mutuo respeto. ${ }^{9}$ Los últimos datos disponibles confirman, año tras año, su progresivo aumento. La custodia compartida fue otorgada en el $24,6 \%$ de los casos de divorcio, un 16,1\% más que el año anterior (INE, 2016). ${ }^{10}$

Sentado el anterior precedente, hay que reparar en que los beneficios y bondades de la custodia compartida y la manifestación general a favor de su establecimiento, no implica que siempre deba adoptarse tal régimen, pues es preciso "atender al caso concreto, considerando los criterios y garantías del art. 92 C.c." 11 Por lo que, no en todos los casos, el interés del menor aconseja la custodia compartida.

1.2. Hijos e hijas expuestos a la violencia doméstica y de género: la concreción del "interés del menor"

Se afirma con razón que, la historia del niño o de la niña no es ajena a la historia de pareja (vid. Atenciano Jiménez 2009: 267, Ordóñez Fernández y González Sánchez

\footnotetext{
${ }^{6}$ Vid. STS no 390/2015, de 26 de junio. Ponente José A. Seijas Quintana.

${ }^{7}$ Vid. el FJ4 de la STS de 1 de octubre de 2010 (RJ 2010/7302. Ponente: Encarnación Roca Trías.

${ }^{8}$ La STS de 22 de julio de 2011 señala a respecto que "las relaciones entre los cónyuges por sí solas no son relevantes ni irrelevantes para determinar la guarda y custodia compartida. Solo se convierten en relevantes cuando afecten, perjudicando el interés del menor". Vid. STS 22 de julio 2011 (EDJ 2011/155183).

${ }^{9}$ La STS de 21 de octubre 2015 (RJ 2015/4784), señala que la custodia compartida conlleva como premisa la necesidad de que entre los padres exista una relación de mutuo respeto en sus relaciones personales que permita la adopción actitudes y conductas que beneficien al menor, que no perturben su desarrollo emocional y que pese a la ruptura afectiva de los progenitores se mantenga un marco familiar de referencia que sustente un crecimiento armónico de su personalidad.

${ }^{10}$ Vid. Estadística de Nulidades, Separaciones y Divorcios, Año 2015. Nota de prensa INE de 29 de septiembre de 2016: 1-6. Disponible http://www.ine.es/prensa/np990.pdf.

${ }^{11}$ Vid. STS de 9 de mayo de 2017 Sentencia: 280/2017 Número Recurso: 1432/2016 Ponente: $M^{\mathrm{a}}$ de los Ángeles Parra Lucán.
} 
2012: 35); así, para la concreción de su interés, en aquellos supuestos en los que la unidad familiar presenta disfunciones por situaciones de ruptura que se anidan en un entorno familiar violento o conflictivo, debe ponderarse la necesaria prevención de la extensión de la violencia doméstica y de género a los hijos e hijas y los derechos paternofiliales. A nuestro modo de ver, y con la precisa cautela, hay que superar la idea estereotipada que afirma que el maltratador no tiene por qué ser un mal padre, y que para los niños, niñas y adolescentes, es mejor mantener relación y contacto con su progenitor violento, que estar apartado de él. Y es que, en este punto, debe recordarse que el/la menor es, ante todo, objeto de protección, pero también sujeto titular de derechos.

Como sujeto titular de derechos, tiene el derecho fundamental a seguir manteniendo contacto y relaciones de carácter estable con ambos progenitores. Este derecho protege su dignidad como persona e implica la necesidad de disfrutar de la relación materna y paterna; no sólo como derecho que le corresponde, sino como derecho del que es titular autónomo. Todo ello para satisfacer sus necesidades básicas, tanto materiales, físicas y educativas, como "emocionales y afectivas" (art. 2 apartado a) de la Ley Orgánica 1/1996, de 15 de enero, de Protección Jurídica del Menor). Derecho de relación que, como es sabido, es también un derecho-deber del padre, "cuya subordinación al interés y beneficio preferente del hijo no excluye la presencia de un interés y beneficio propio" (vid. Acuña San Martín 2014: 147). En este contexto, conjugar el derecho recíproco de relación paterno filial, siempre resultará difícil y complejo. Pero la primera pauta a seguir, en caso de que no puedan respetarse todos los intereses legítimos concurrentes, es la de priorizar el interés superior del menor, sobre cualquier otro interés legítimo que pudiera concurrir.

Como objeto de protección, el "favor fili" recomienda que su vida y desarrollo tenga lugar en un entorno familiar adecuado y "libre de violencia". Así lo dispone el art. 2 aparatado c) de la LO 1/1996, en su nueva redacción dada por la LO 8/2015 de 22 de julio, de modificación del sistema de protección a la infancia y a la adolescencia. ${ }^{12} \mathrm{Se}$

\footnotetext{
${ }^{12}$ La propia Exposición de Motivos de la Ley Orgánica 8/2015, de 22 de julio, señala al respecto estas consideraciones: "Cualquier forma de violencia ejercida sobre un menor es injustificable. Entre ellas, es singularmente atroz la violencia que sufren quienes viven y crecen en un entorno familiar donde está
} 
trata de un pilar fundamental para garantizar a niños, niñas y adolescentes el disfrute de una vida digna. Y es aquí donde, en mi opinión, el legislador concreta el interés del menor que, en todos los procedimientos relacionados con la violencia de género, queda claramente definido. Sin perjuicio, no obstante, de que dicha noción debe seguir siendo "flexible y adaptable, debiendo ajustarse y definirse de forma individual, con arreglo a la situación concreta del niño o niña afectado y teniendo en cuenta el contexto, las necesidades y las circunstancias específicas personales" (vid. Comité de los derechos del niño 2013: 4 y 9).

Y no admite matices que cuando el contexto familiar revela que el o la menor ha vivido expuesto a episodios repetidos de actos de violencia ejercida por el padre hacia la madre -como ocurre en un porcentaje muy elevado de casos-, ${ }^{13}$ no ha sido preservado y sufre las consecuencias de una atroz violencia extendida, con los riesgos inherentes a tal consideración. Los estudios revelan que el maltrato a la mujer se extiende a sus hijos e hijas, afectando negativamente su bienestar y su desarrollo, con secuelas a largo plazo (vid. Sepúlveda García de la Torre 2006: 163). Pues a pesar de no haber recibido agresión directa, su vida se desenvuelve en un ambiente de violencia psicológica, que no dudamos

presente la violencia de género. Esta forma de violencia afecta a los menores de muchas formas. En primer lugar, condicionando su bienestar y su desarrollo. En segundo lugar, causándoles serios problemas de salud. En tercer lugar, convirtiéndolos en instrumento para ejercer dominio y violencia sobre la mujer. Y, finalmente, favoreciendo la transmisión intergeneracional de estas conductas violentas sobre la mujer por parte de sus parejas o ex parejas. La exposición de los menores a esta forma de violencia en el hogar, lugar en el que precisamente deberían estar más protegidos, los convierte también en víctimas de la misma.

${ }^{13}$ Una reciente investigación analiza las violencias vividas por las mujeres y sus hijos e hijas y arroja los siguientes resultados: Durante las violencias físicas sufridas por la madre, en un 29,8\% de los casos había un hijo/a presente de la relación y en el $22,1 \%$ había dos; (...) el $97 \%$ de los casos analizados la frecuencia de la violencia psíquica es de muchas veces (más de seis). La presencia de los hijos/as durante la violencia descrita en la misma asciende a 95,7\%, nacidos de la relación un 83,5\% de los niños y de las niñas presentes. En cuanto a la frecuencia en la exposición, en un 97,3\% estuvieron presentes muchas veces. Vid. Reyes, Paula. (2015). "Menores y violencia de género: de invisibles a visibles." Anales de la Cátedra Francisco Suárez, 49 (2015), p. 191. Igualmente, la Macroencuesta de violencia contra la mujer (2015) arroja los siguientes resultados: "De las mujeres que han contestado que sus hijos e hijas presenciaron o escucharon los episodios de violencia, el 92,5\% afirma que los hijos e hijas eran menores de 18 años cuando sucedieron los hechos. De las mujeres que han contestado que sus hijos e hijas presenciaron o escucharon los episodios de violencia de género y que estos hijos eran menores de 18 años cuando sucedieron los hechos, el 64,2\% afirma que estos hijos e hijas menores sufrieron a su vez violencia de los agresores de sus madres. Vid. Macroencuesta de violencia contra la mujer 2015. Colección contra la violencia de género n ${ }^{\circ} 22$. Ministerio de Sanidad, Servicios sociales e Igualdad. Centro de publicaciones, pp. 172 y 173. Esta investigación ha sido realizada por Verónica de Miguel Luken. Recurso en línea:

http://www.violenciagenero.msssi.gob.es/violenciaEnCifras/estudios/colecciones/pdf/Libro_22_Macroen cuesta2015.pdf. 
en calificar como un auténtico maltrato infantil. Y lo que es peor, cuando la madre, tras superar difíciles obstáculos de diversa índole ${ }^{14}$ decide denunciar y romper el ciclo de la violencia, son los hijos e hijas quienes se convierten en el instrumento para seguir ejerciendo control y maltrato hacia la mujer, con directa repercusión en ellos. Se afirma que estas niñas y niños tienen un elevado riesgo de ser objeto de malos tratos físicos, psicológicos, sexuales y ser atendidos de forma negligente, en el contacto con el maltratador (véase Atenciano Jiménez 2009: 267).

Sin embargo, a pesar de estas contrastadas evidencias, nuestros Tribunales se han mostrado resistentes y en ocasiones priman los derechos de paternidad, ante la seguridad, integridad y la recuperación del menor, que exige protegerle de un entorno familiar violento. Resistencias a la retirada de la guarda y custodia, privación de la patria potestad y suspensión del régimen de visitas a padres maltratadores. Incluso otorgando la custodia compartida cuando el padre es condenado por violencia de género, a pesar de la prohibición legal.

\section{Custodia compartida y violencia de género. Previsiones legales y nueva línea jurisprudencial}

2.1.- Prohibición expresa ex art. 92.7 C.c. y su conexión con la normativa protectora de la infancia y adolescencia

El apartado 7 del art. 92 C.c. y la legislación autonómica, ${ }^{15}$ prohíben expresamente la guarda y custodia conjunta (no menciona la exclusiva o monoparental) cuando alguno

\footnotetext{
${ }^{14}$ Dificultades que Bodelón agrupa en dos: en el primer grupo se encontrarían las de tipo social/ psicológico; y en segundo, las de tipo institucional y jurídico (vid. Bodelón 2014: 145).

${ }^{15}$ Sobre la prohibición expresa puede verse: En Cataluña, la Ley 25/2010, de 29 de julio, del Libro Segundo del Código Civil de Cataluña, relativo a la persona y la familia, en el art. 233-11 apartado 3; En Aragón, el Decreto Legislativo 1/2011, de 22 de marzo, del Gobierno de Aragón, por el que se aprueba, con el título de "Código del Derecho Foral de Aragón", en el apartado 6 del art. 80. ); la Ley Foral de Navarra 3/2011, de 17 de marzo, sobre custodia de los hijos en los casos de ruptura de la convivencia de los padres establece en el en el apartado 8 del art. 3; y en la Ley 5/2011, de 1 de abril, de la Generalitat Valenciana, de Relaciones Familiares de los hijos e hijas cuyos progenitores no conviven, la prohibición está prevista en el apartado 6 del art. 4 . Y en la más reciente la Ley 7/2015, de 30 de junio, de relaciones familiares en supuestos de separación o ruptura de los progenitores, del País Vasco, en los apartados 3 y 4 del art. 9.
} 
de los padres esté incurso en un procedimiento penal incoado por atentar contra la vida, la integridad física, la libertad, la integridad moral o la libertad o indemnidad sexual; y tampoco, cuando el Juez advierta la existencia de indicios fundados en violencia doméstica (elude la violencia de género). Ciertamente, la redacción del precepto presenta omisiones e imprecisiones que la doctrina ha criticado. Bien por resultar incompleto (vid. Ureña Carrazo 2016); por falta de rigor técnico, dudas interpretativas, rozando la inconstitucionalidad (vid. García Rubio 2006: 99.); y vaguedades que dificultan su aplicación (vid. Ruiz de la Cuesta Fernández 2013: 100-112). Así, la aplicación práctica del art. 92.7 C.c. ofrece respuestas judiciales dispares y contradictorias. Algunas matizan la interpretación del art. 92.7 C.c. no aplicando la prohibición expresa y estableciendo la custodia conjunta, si se estima que de esta forma queda salvaguardado el superior interés del menor. ${ }^{16}$ Otras, más allá de lo previsto en el supuesto de hecho del precepto, acuerdan la suspensión del mal llamado "régimen de visitas".

Sobre el particular, resulta interesante traer a colación el art. 95 bis 5 del Anteproyecto de Ley sobre el ejercicio de la corresponsabilidad parental y otras medidas a adoptar tras la ruptura de la convivencia, ${ }^{17}$ que introdujo una modificación importante en este punto; y que, a fecha de hoy, recobra especial interés. El precitado art. 95 bis 5, extiende la prohibición a la custodia individual, a la compartida y al régimen de estancia, relación y comunicación (derecho de visitas) de los hijos e hijas con el progenitor maltratador. Se afirma que la proyectada reforma no vio la luz en la pasada legislatura, por presiones desde distintos sectores y serias controversias, a propósito de la nueva regulación de la custodia compartida (véase ampliamente, González del Pozo y Campo Izquierdo 2016); con incidencia también en el precepto que ahora comentamos. Sin ánimo de exhaustividad, cabe reseñar que algunas de sus previsiones se encuentra en línea con

\footnotetext{
${ }^{16}$ En ocasiones, cuando queda probado en autos que, ni durante la convivencia ni con posterioridad a la misma, se ha producido ningún otro episodio violento; considerándose que se ha tratado de un hecho aislado y sin que los menores estén afectados en su bienestar y desarrollo.

${ }^{17}$ El 19 de julio de 2013 el Gobierno aprobó, en la reunión del Consejo de Ministros, el Anteproyecto de Ley sobre el Ejercicio de la Corresponsabilidad Parental en caso de Nulidad, Separación o Divorcio (EDL 2013/180450), más conocido como Anteproyecto de Ley de "custodia compartida". Tras la aprobación del texto inicial, se evacuaron los preceptivos informes del Consejo General del Poder Judicial y del Consejo Fiscal (ambos en septiembre de 2013) que contienen numerosas sugerencias. Una de ellas el nuevo título, para incluir a los progenitores que vivieren separados y no estuvieren unidos por vínculo matrimonial (parejas de hecho).
} 
las modificaciones introducidas en materia de protección efectiva a los hijos e hijas víctimas de violencia doméstica o de género; y que serán reforzadas, tras el acuerdo político alcanzado para la aprobación del Pacto de Estado contra la Violencia de Género.

De gran trascendencia ha sido la citada LO 8/2015 de 22 de julio, que modifica el art 1 de la LO 1/2004 de 28 de diciembre, de Medidas de Protección Integral contra la Violencia de Género, para incluir a los menores como víctimas directas de esta violencia. ${ }^{18}$ Se supera de esta forma el denunciado "olvido de la infancia y su consideración referencial o indirecta en la ley integral como víctimas de las agresiones sexistas que pueden producirse en el ámbito doméstico o familiar" (Villagrasa 2015: 22). Asimismo, esta Ley, da nueva redacción a los arts. 61.2, 65 y 66 de la Ley Orgánica 1/2004,19 que prevén la suspensión de la patria potestad o la custodia y la suspensión del régimen de visitas, estancia, relación o comunicación con los hijos e hijas. ${ }^{20}$ Reformas que también están el línea con las previsiones que unos meses antes hiciera el Estatuto de la víctima, aprobado por Ley 4/2015, de 27 de abril, en desarrollo del Convenio de Estambul (2011) ${ }^{21}$ que modifica el art. 544 ter 7 LECRr, (medidas civiles determinadas en el ámbito de la orden de protección) ${ }^{22}$; e introduce ex novo el art. 544 quinquíes de la

\footnotetext{
${ }^{18}$ Así el punto 2, del art. 1, al referirse al objeto de la ley, señala que "por esta ley se establecen medidas de protección integral cuya finalidad es prevenir, sancionar y erradicar esta violencia y prestar asistencia a las mujeres, a sus hijos menores y a los menores sujetos a su tutela, o guarda y custodia, víctimas de esta violencia".

${ }^{19}$ Por esta Ley se crearon los Juzgados de Violencia sobre la Mujer que serán competentes de un procedimiento civil cuando concurran los requisitos del art. 87 ter LOPJ. Competencia que solo subsiste, en tanto alguna de las partes del proceso civil se encuentre imputada por actos de violencia de género.

${ }^{20} \mathrm{El}$ art. 65 bajo la rúbrica "De las medidas de suspensión de la patria potestad o la custodia de menores" prevé la suspensión para el inculpado de la patria potestad, guarda o de la custodia de los menores a que se refiera. Y añade que, para el caso de no acordar la suspensión, "el Juez deberá pronunciarse en todo caso sobre la forma en la que se ejercerá la patria potestad y, en su caso, la guarda y custodia, (...) de los menores. Y el art. 66 bajo la rúbrica "De la medida de suspensión del régimen de visitas, estancia, relación o comunicación con los menores", señala -para los casos en que ya existiera un régimen de visitas judicialmente establecido- que "El Juez podrá ordenar la suspensión del régimen de visitas, estancia, relación o comunicación del inculpado por violencia de género respecto de los menores que dependan de él. Si no acordara la suspensión, el Juez deberá pronunciarse en todo caso sobre la forma en que se ejercerá el régimen de estancia, relación o comunicación del inculpado por violencia de género respecto de los menores que dependan del mismo.

${ }^{21}$ Instrumento de ratificación del Convenio del Consejo de Europa sobre prevención y lucha contra la violencia sobre la mujer y la violencia doméstica, firmado en Estambul el día 11 de mayo de 2011 (B.O.E de 6 de junio de 2014).

${ }^{22}$ Como es sabido, antes de la reforma, estas medidas se regían por el principio de rogación; pero ahora, cuando existan menores o personas con capacidad judicialmente modificada que convivan con la víctima y
} 
LECr, ${ }^{23}$ Todo ello sin perjuicio de las medidas previstas en el art. 158 C.c. en su nueva redacción dada por la Ley 26/2015 de 28 de julio, de modificación del sistema de protección a la infancia y a la adolescencia, que opera una modificación en los números 4, 5 y 6 , y permite adoptar mecanismos protectores, tanto respecto al menor víctima de los malos tratos, como en relación con quienes, sin ser víctimas, puedan encontrarse en situación de riesgo; incluido la sustracción internacional de menores, a fin de apartarles de un peligro o de evitarle perjuicios.

Puede colegirse que tras reciente normativa se refuerza de la protección de niños y niñas que viven expuestos a la violencia de género ejercida sobre su madre. Pero para su verdadera implementación, es urgente diseñar mecanismos rápidos y eficientes para garantizarles el acceso a los servicios de asistencia y apoyo, así como adoptar medidas de protección; y la necesidad de pronunciamiento expreso, en todo caso, por parte del o de la Juez competente, incluso de oficio, y aún cuando no se hubieren instado ante él medidas civiles. Así, el fundamento del art. 92.7 C.c. y la normativa conexa anteriormente citada tiene un hilo conductor común; y es que, en la ordenación de la custodia, individual o compartida, y el derecho de estancia, relación, y comunicación del progenitor violento con los menores, debe primar el principio de preservar al menor de una situación de riesgo.

2.2. Cuestiones controvertidas que plantea la aplicación práctica del art. 92.7 C.c.

Como se ha indicado, el art. 92.7 C.c. prohíbe terminantemente el establecimiento de la custodia compartida ("no procederá") cuando se dan los supuestos de hecho que contempla la norma; esto es, cuando alguno de los progenitores esté incurso en un

dependan de ella, el Juez deberá pronunciarse en todo caso, incluso de oficio, sobre la pertinencia de su adopción.

${ }^{23}$ Este precepto alude a que cuando se investigue alguno de los delitos mencionados en el art. 57 del C.P. (homicidio, lesiones, delitos contra la integridad moral, etc.) el juez podrá acordar medidas en protección de las víctimas menores o con capacidad judicialmente modificada, tales como la suspensión del ejercicio de la patria potestad, etc. Pero con la particularidad de que las medidas del art. 544 quinquies se pueden extender "sine die", mientras que las medidas civiles acordadas en la orden de protección tiene una vigencia de 30 días) 
procedimiento penal incoado por atentar contra la vida, la integridad física, la libertad, la integridad moral o la libertad o indemnidad sexual; o cuando el Juez advierta la existencia de indicios fundados en violencia doméstica. De la lectura del precepto surgen dudas interpretativas o cuestiones que deja inconclusas y que matizaremos a la luz de la jurisprudencia y de lo previsto en el citado Anteproyecto de responsabilidad parental.

2.2.1. ¿Qué sucede en los supuestos en que se solicita la custodia compartida y hay un delito que no está incluido entre los que, conforme al artículo 92.7 C.c. excluyen este modelo de guarda?

Debe repararse en que los tipos delictivos a los que se refiere el art. 92.7 C.c. son: atentado contra la vida, la integridad física, la libertad, la integridad moral o la libertad e indemnidad sexual, ${ }^{24}$ del otro cónyuge o de los hijos e hijas que convivan con ambos. Pero ¿cabe una interpretación extensiva a otros tipos penales? Pues la jurisprudencia matiza, caso por caso, teniendo en cuenta siempre el interés del menor; pero particularmente se pronuncia sobre el delito de amenazas:

- La STS de 7 de abril de 2011, ${ }^{25}$ denegó la concesión de la guarda y custodia compartida motivando en la resolución que el marido fue condenado por amenazas al cónyuge; y aunque reconoce que se trata de un delito que no está incluido entre los que, conforme al artículo 92.7 C.c. excluyen la guarda compartida, sí puede constituir un indicio de violencia o de situación conflictiva entre los cónyuges, en cuyo caso, no procede la guarda conjunta.

- En la misma línea, la STS de 4 de febrero de $2016^{26}$ señala que la guarda y custodia compartida es incompatible con la condena de uno de los progenitores

\footnotetext{
${ }^{24}$ Por remisión serían: a) los delitos de homicidio, asesinato e inducción al suicidio; b) los delitos de lesiones; c) los delitos contra la libertad (detención ilegal, amenazas y coacciones); d) el delito de torturas y otros delitos contra la integridad moral; y e) los delitos contra a libertad e indemnidad sexual (agresiones sexuales, abusos sexuales, acoso sexual, exhibicionismo, prostitución y corrupción de menores).

${ }^{25}$ Vid. STS (Sala de lo Penal) núm. 252/2011 de 7 de abril de 2011. Ponente Perfecto A. Andrés Ibañez. Id Cendoj: 28079120012011100007.

${ }^{26}$ Vid. STS (Sala de lo civil) núm. 36/2016) de 4 de febrero. Ponente: Seijas Quintana). Id Cendoj: 28079110012016100010.
} 
(padre) por un delito de amenazas en el ámbito familiar (arts. $171.4^{\circ}$ y $5^{\circ}$, en relación con los artículos $57.3^{\circ}$ y $48.2^{\circ} \mathrm{CP}$ ). La condena se fundamenta en los siguientes hechos probados: [el demandado] ... "sobre las 20:00 horas del día 6 de enero de 2015, cuando su ex-pareja, (...) iba a proceder a la entrega de los hijos comunes en el domicilio del acusado, y con ánimo de causarle un temor de sufrir un menoscabo en su integridad corporal, le dijo "como no me den la custodia compartida te arrancio la piel a tiras, como me quites la custodia compartida aunque sea lo último que haga, te meto una hostia aquí mismo, mentirosa de la hostia, esto va a acabar mal para todos, perra de la hostia, te va a tocar la gorda, la gorda te va a tocar". Consta probado que el señor "se arrepintió de sus actos inmediatamente, motivo por el que asumió su responsabilidad mostrando su conformidad con la acusación del Ministerio Fiscal. Y, consciente de que aquel hecho se había producido por su estado de ansiedad y depresión, acudió a la consulta de un psiquiatra para tratar esos problemas". Pero el TS se muestra contundente y señala que "sus razones no pueden dejar sin repuesta hechos indiscutidos de violencia en el ámbito familiar, con evidente repercusión en los hijos, que viven en un entorno de violencia, del que son también víctimas, directa o indirectamente, y a quienes el sistema de guarda compartida propuesto por el progenitor paterno y acordado en la sentencia les colocaría en una situación de riesgo por extensión al que sufre su madre, directamente amenazada". El Alto Tribunal recuerda su doctrina sobre la custodia compartida, señalando expresamente la necesidad de que entre los progenitores exista una relación de mutuo respeto que permita la adopción de actitudes y conductas que beneficien al menor y no perturben su desarrollo emocional. El Fundamento Jurídico $2^{\circ}$ alude al art. 92.7 C.c. relacionándolo con el art. 2 de la LO 8/2015 en donde se recuerda que el "interés superior de las y los menores" debe priorizar un entorno libre de violencia y en caso de concurrencia con otros intereses legítimos, siempre deberá primar sobre cualquier otro. La Sala asume la instancia y mantiene la guarda y custodia de los hijos en favor de la madre y se deja a la determinación del Juzgado, en trámite de ejecución de la sentencia, la fijación del régimen de comunicaciones y estancias de los menores con su padre. 
Nótese que art. 92 bis 5, del Anteproyecto de Ley de Responsabilidad parental, con una redacción mas ajustada señala como tipos delictivos que excluyen la custodia compartida, el delito de violencia doméstica ${ }^{27}$ o de género ${ }^{28}$ por atentar contra la vida, la integridad física, la libertad, la integridad moral o la libertad e indemnidad sexual, la intimidad, incluyendo el derecho a la propia imagen o al honor del otro cónyuge o de los hijos que convivan con ambos hasta la extinción de la responsabilidad penal”. Al respecto cabe reseñar que al igual que ha ocurrido con la vigente regulación (art. 92.7 C.c.), no se trata de una lista cerrada de figuras delictivas; por lo que cabrá interpretación; en este sentido recobra interés reparar en que este precepto omite las faltas, hoy suprimidas y reconvertidas en delitos leves, ${ }^{29}$ por lo que, de cara a una futura regulación, sería conveniente incluirlos dentro del ámbito de aplicación de la norma. Y aunque las amenazas y coacciones entrarían en el ámbito de los delitos contra la libertad, por las dudas interpretativas que ha generado el precepto, cabría incluirlas expresamente. Al igual que sería necesario incluir expresamente el nuevo delito conocido como stalking (art. 172 ter) CP), ${ }^{30}$ referido a conductas de acoso (acecho) y por el que se somete a la víctima a persecuciones o vigilancias constantes, llamadas o mensajes reiterados, $\mathrm{u}$ otros actos continuos de hostigamiento, que desgraciadamente suelen ser comunes en este contexto.

\footnotetext{
${ }^{27} \mathrm{La}$ violencia doméstica o intrafamiliar es la que se produce entre ascendientes, descendientes o hermanos, propios o del cónyuge o conviviente, o sobre menores o incapaces que se hallen sujetos a la patria potestad, tutela curatela acogimiento o guarda de hecho del cónyuge o conviviente o que con él convivan, o sobre otra persona amparada por cualquier relación por la que se encuentren integrados en el núcleo de convivencia familiar, siempre y cuando no se trate de hechos cometidos contra la mujer por su pareja o ex pareja varón (bien se trate de matrimonio o de otra relación de afectividad análoga) (Guía practica de la Ley Orgánica 1/2004 2016: 29).

${ }^{28} \mathrm{La}$ violencia de género es la violencia o las diferentes violencias inferidas por hombres contra mujeres por el mero hecho de ser mujeres y constituye manifestación de relaciones de poder históricamente desiguales (...)La más relevante, cuantitativamente, tiene lugar en el ámbito de convivencia o relación familiar, muy especialmente en el ámbito de la pareja o ex pareja. Ésta tiene en común con la violencia doméstica, exclusivamente, el ámbito o el lugar en que se desarrollan sus manifestaciones más numerosas (Guía practica de la Ley Orgánica 1/2004 2016: 30).

${ }^{29}$ Suprimidas por la Ley Orgánica 1/2015, de 30 de marzo, por la que se modifica la Ley Orgánica 10/1995, de 23 de Noviembre, del Código Penal.

${ }^{30}$ La Ley Orgánica 1/2015, de 30 de marzo, por la que se modifica la Ley Orgánica 10/1995, de 23 de Noviembre, del Código Penal, tipifica en el art. 172 ter el nuevo delito de stalking dentro de los delitos contra la libertad.
} 
2.2.2. ¿Cómo interpretar el inciso estar "incurso en un proceso penal" y la existencia de "indicios fundados de violencia doméstica"

El art. 92.7 C.c. señala que no procederá la custodia conjunta en dos supuestos: cuando cualquiera de los progenitores esté incurso en un procedimiento penal y tampoco, cuando existan indicios fundados de violencia de género (no menciona que haya condena por sentencia penal firme). Sin duda, estas dos expresiones son las que se nos presentan como más espinosas. Al respecto haremos algunas matizaciones de cara a una futura modificación, conectando el vigente art. 92.7 C.c. con el art. 95 bis 5 del Anteproyecto que introduce importantes modificaciones, unas acertadas y otras no exentas de algún reparo. De la dicción de éste precepto se deduce que la comisión de un delito de violencia doméstica o de género excluirá la guarda y custodia individual y compartida en los siguientes supuestos:

$1^{\circ}$. No procederá cuando "uno de los progenitores haya sido condenado penalmente por sentencia firme"; este inciso, actualmente omitido en el art. 92.7 C.c., no plantea dudas interpretativas, pero su inclusión expresa ya había sido reivindicada por la doctrina (vid. García Rubio y Otero Crespo 2006: 99). Por lo que se estima acertada, pues la condena penal firme es una condición legal objetiva, que imposibilitaría la custodia al progenitor violento en ninguna de sus modalidades, ni de forma individual, ni mucho menos compartida. Así se ha recogido en nuestros Tribunales:

- La SAP Valencia, de 23 de mayo de 2016, señala que no se dan los presupuestos para conceder la custodia compartida de los menores pues el padre ha sido condenado por delito de malos tratos en el ámbito familiar, con pena de prisión y orden de alejamiento y comunicación respecto de la madre. En igual sentido la SAP de Barcelona de 13 de noviembre de 2015 señala que no es posible la custodia compartida por faltar la indispensable comunicación y colaboración mínima entre 
los progenitores, en tanto persista la orden de alejamiento. ${ }^{31}$

- La SAP de Santander de 9 de marzo de 2016, ${ }^{32}$ revoca la decisión del Juzgado de Violencia sobre la Mujer número 1 de Santander, que había otorgado la custodia compartida de los hijos menores (14 y 7 años) y cuyo progenitor fue condenado por un delito de violencia de género. Esta decisión se fundamenta en base al testimonio del hijo mayor, que manifestó querer estar con su padre tanto tiempo como con su madre, así como en el informe favorable del equipo psicosocial; y además, según consta, en que el progenitor no es una persona violenta. La Audiencia, por el contrario, recuerda que "una cosa es la lógica conflictividad que puede existir entre los progenitores como consecuencia de la ruptura, y otra distinta, que ese marco de relaciones se vea tachado por una injustificable condena por un delito de violencia de género". Y añade que tal condena "aparta al padre del entorno familiar y de la comunicación con la madre, lo que va a imposibilitar el ejercicio compartido de la función parental adecuado al interés de sus dos hijos". En consecuencia y pese al informe psicosocial, la Sala atribuye la guarda y custodia sobre los hijos menores a la madre".

Pero como se ha anticipado, el proyectado art. 92 bis 5 añade que cuando hay condena penal por sentencia firme, tampoco procedería el régimen de régimen de estancia, relación y comunicación. Esta cuestión se presenta compleja, cuando, hasta ahora, por parte de los Tribunales, la tendencia ha sido establecer un régimen de relación, si bien restrictivo y en ocasiones supervisado por terceros, generalmente familiares, y en los Puntos de Encuentro (allí donde existen). En este aspecto incidiremos después.

$2^{\circ}$. No procederá la custodia conjunta cuando uno de los progenitores "esté incurso en un proceso penal" (ex art. 92.7 C.c.), lo que se ha interpretado como estar investigado (antes imputado), condenado o penado; pero no exige el precepto que se haya dictado

\footnotetext{
${ }^{31}$ Vid. SAP de Barcelona (Sección 12aa) Sentencia núm. 739/2015 de 13 noviembre. (JUR 2016\10519) Ponente: Pascual Ortuño Muñoz

32 Vid. SAP de Santander 9 de marzo de 2016 (sentencia número 153/2016). Ponente: Fernández Díez.
} 
ninguna resolución judicial ni motivada, ni firme. El proyectado art. 92 bis 5 proscribe la guarda y custodia, ni individual ni compartida, (en este supuesto no menciona el régimen de estancia, relación y comunicación), cuando se haya dictado una "resolución judicial motivada" en la que se constaten "indicios fundados y racionales de criminalidad". Al respecto los Tribunales resuelven con cautela:

- La STS (Sala de lo civil) de 26 de mayo de 2016 revoca la custodia compartida de un niño de siete años concedida a sus padres por Audiencia Provincial de Coruña, y la otorga en exclusiva a la madre. Su fundamento está en "la falta total de respeto, y posición abusiva y dominante" que mantenía el progenitor respecto a la mujer. En el caso de autos, al padre le había sido incoado por la vía penal auto de procedimiento abreviado (no firme) por un delito de violencia en el ámbito familiar y coacciones a su mujer. En el auto de incoación de procedimiento penal consta que el padre decidió iniciar una situación de acoso con su exmujer, "que tuvo proyección y que hubo de vivir más de una vez el hijo menor". "Rondaba las inmediaciones del domicilio de la mujer, o lugares que sabía que frecuentaba, realizando gestos provocativos, profiriendo insultos, contra ella o personas de su entorno. Los intercambios del menor, cuando intervenía la madre o familiares de ella, los convertía en situaciones conflictivas". Por ello, el TS "partiendo del delito sometido a enjuiciamiento y de las actitudes del padre, ejerciendo una posición irrespetuosa de abuso y dominación, es impensable que pueda llevarse a buen puerto un sistema de custodia compartida que exige un mínimo de respeto y actitud colaborativa, que en este caso brilla por su ausencia”. Por lo que procede a casar la sentencia por infracción de la doctrina jurisprudencial, dado que la referida conducta del padre, probada en la sentencia recurrida, "desaconseja un régimen de custodia compartida, pues afectaría negativamente al interés del menor, quien requiere un sistema de convivencia pacífico y estable emocionalmente".

- La SAP Valencia, (Sección 10ª) de 25 de noviembre de 2015 confirma la guarda materna, pues al continuar abiertas las diligencias penales contra el padre por 
procedimiento de violencia de género no puede establecerse la custodia compartida. Además, se motiva la decisión porque, ante la escasa edad de las hijas, los psicólogos especialistas señalan, salvo excepciones, que es conveniente en estos casos evitar cambios frecuentes de casa y de hábitos.

En este punto cabe pronunciarse sobre si la denuncia y el auto de admisión a trámite (resolución motivada) será suficientes para no acordar la custodia ni individual, ni compartida. Nosotros entendemos que sí, por la extrema cautela con que, en interés del menor, hay que actuar en estos casos. Es más, en ocasiones, con sumo acierto, los Tribunales estiman que, pese al archivo de la denuncia, si existe un ambiente conflictivo, ello va en contra de la adopción de la custodia compartida. ${ }^{33}$ Pero en este punto surge también el fantasma de las denuncias falsas, a las que se califica de "instrumentales"34 a pesar de que los últimos datos disponibles revelan un "escasísimo porcentaje". ${ }^{35}$ Nótese que el Anteproyecto en el art. 92 bis 5 in fine introduce la siguiente previsión "si se alegasen en la demanda o en el transcurso del procedimiento, hechos o circunstancias relacionados con los párrafos anteriores que se revelasen inciertos, el Juez deducirá testimonio de las actuaciones y lo pondrá en conocimiento del Ministerio Fiscal a fin de que se determinen las responsabilidades a que haya lugar”.

$3^{\circ}$. La última previsión que incluye el proyectado art. 92 bis 5 es que tampoco procede la custodia compartida cuando "el Juez del procedimiento civil advierta, de las alegaciones de las partes y las pruebas practicadas, la existencia de indicios fundados de la comisión de tales hechos por el progenitor, siempre que el delito no estuviera prescrito". Sobre el particular se cuestiona que el derecho a la presunción de inocencia

\footnotetext{
${ }^{33}$ Al respecto, véase la SAP Asturias, Sec. 4. a, 210/2014, de 25 de julio (SP/SENT/780204).

${ }^{34}$ Esto es, por el derecho a asistencia social integral, asistencia jurídica gratuita, percepción de la Renta Activa de Inserción, etc. Pero cabe recordar que el Estatuto de la Víctima del Delito aprobado por Ley 4/2015, de 27 de abril contempla, en su artículo quinto la obligación de reembolso de las ayudas percibidas "si fuera condenada por denuncia falsa o simulación de delito, la persona que se hubiera beneficiado de subvenciones o ayudas percibidas por su condición de víctima”.

${ }^{35} \mathrm{Al}$ respecto, la Fiscalía especializada en Violencia sobre la Mujer en su memoria anual (2016) señala que el "escasísimo porcentaje" (0,0079\%) (vid. Memoria Anual de la Fiscalía General del Estado 2016).
} 
queda seriamente comprometido. Además, a juicio del Consejo de Estado, ${ }^{36}$ la inclusión del inciso "siempre que el delito no estuviera prescrito", no es acertada; pues atribuye al Juez civil competencia para pronunciarse, a efectos prejudiciales, sobre aspectos de naturaleza penal en los que ni puede ni debe entrar, dado que el conocimiento de tales cuestiones, como el de toda la materia penal, se encuentra íntegramente reservado al orden jurisdiccional penal.

\subsection{3.- Sentencia absolutoria y revisión del régimen de guarda y custodia}

Nada contempla el vigente art. 92.7 C.c. sobre si las medidas adoptadas acerca de la custodia compartida serán revisables. La Circular 6/2011 de la Fiscalía General del Estado sobre criterios de actuación especializada del Ministerio Fiscal en relación a la Violencia sobre la Mujer, ya estableció que la custodia de los hijos e hijas será revisable cuando se dicte resolución que ponga fin al proceso penal, entendiendo por tal la existencia de sentencia absolutoria firme. La jurisprudencia así lo ha entendido y el art. 92 bis 5 del Anteproyecto señala al respecto que "La Sentencia absolutoria, el sobreseimiento libre o el archivo definitivo dictado en el referido proceso penal será causa de revisión del régimen de guarda y custodia a petición de parte." Así, concluido el proceso penal con sentencia absolutoria cabe otorgar la custodia compartida:

- La Sentencia del Juzgado n $^{\circ} 1$ de Violencia sobre la Mujer de Barcelona, de 31 de octubre de 2007, ${ }^{37}$ atribuyo la guarda y custodia compartida del hijo común señalando que "no constituye un impedimento para ello la denuncia presentada por la madre contra el padre por delitos de malos tratos y amenazas al haberse acreditado su absolución en vía penal". Evidentemente la situación entre ambos

\footnotetext{
36 Vid. Dictámen del Consejo de Estado sobre Anteproyecto de ley sobre el ejercicio de la corresponsabilidad parental y otras medidas a adoptar tras la ruptura de la convivencia. (24 de julio de 2014) Número de expediente: 438/2014 (JUSTICIA). Apartado 1.3.4. Recurso disponible: http://www.boe.es/buscar/doc.php?id=CE-D-2014-438

${ }^{37}$ Sentencia del Juzgado $n^{\circ} 1$ de Violencia sobre la Mujer de Barcelona, de 31 de octubre de 2007. Ponente: Carles Tortras Bosch.
} 
padres era enconada y no obstante se entendió que lo mejor para el menor era el régimen de custodia compartida.

- La STS 13 de abril de $2016^{38}$ otorga la custodia compartida en un proceso de modificación de medidas teniendo en cuenta, entre otros aspectos, que el padre fue absuelto del delito de maltrato habitual y amenazas por los que le había denunciado su esposa. En el momento de dictarse la sentencia de divorcio por un Juzgado de El Ejido (13 de junio de 2011), había una denuncia de la madre contra el padre por malos tratos y que había dado lugar a la incoación de causa penal. La Sala señala que "No menos importante a la hora de valorar el cambio de circunstancias es que el padre fue absuelto del delito de maltrato habitual y amenazas, por los que le denunció su esposa". Con anterioridad se habían archivado diligencias penales en las que le denunciaba por abuso contra la menor, resolución que fue confirmada por la Audiencia Provincial, en base a la pericial de los expertos del Juzgado y exploraciones de la menor, llevadas a cabo por el Juez de Instrucción. Para el TS dicha absolución constituye un cambio significativo de las circunstancias, dado que fue uno de los elementos que motivaron la denegación de la custodia compartida, por aplicación del art. 92.7 del C. Civil. Por lo que, se estima el recurso del padre y le otorga la custodia compartida, en interés del menor, al apreciarse un cambio significativo de las circunstancias que se tuvieron en cuenta cuando se adoptó el anterior sistema de custodia, que ya incluía un régimen de visitas al padre (todos los martes y jueves y fines de semana alternos). Asimismo, refiere que la menor tenía 5 años de edad cuando se dictó la sentencia de divorcio, y que ahora tiene 10, un incremento de edad que "constituye en sí mismo una variable que aconseja un contacto más intenso con los dos progenitores". El TS recuerda que tras la sentencia de divorcio se ha modificado la jurisprudencia, de modo que ahora la custodia compartida es el sistema normal, salvo excepciones. Así lo establece en este caso "dada la capacitación de los padres, su implicación, la vinculación de la hija con ambos

38 STS, Civil del 13 de Abril del 2016. Ponente Francisco J. Arroyo Fiestas. Id Cendoj: 28079110012016100238 
progenitores y la proximidad de los domicilios".

En nuestra opinión, y con las debidas cautelas, la sentencia absolutoria firme del progenitor investigado por maltrato, no debería operar ipso iure para establecer de inicio el régimen de custodia compartida. En este contexto, puede presumirse que la relación entre los progenitores es altamente conflictiva, lo que también hace presumir que este sistema de reparto de la convivencia puede acarrear más perjuicios que beneficios. Pero a ello se une otra evidencia que hay que sopesar. Ocurre habitualmente que tras la interposición de la denuncia por un presunto delito de violencia de género, la víctima se acoge a su derecho a no declarar previsto en el art. 416 LECr., por presiones, miedo u otro tipo de dependencias; y ello supone que el procedimiento finalice con la libre absolución o el sobreseimiento provisional. En este punto debe operarse una modificación para evitar, en su caso, la impunidad del investigado y una segunda victimización de la mujer.

Por último y a efectos procesales, reseñar que la revisión del régimen de guarda y custodia se hará conforme al procedimiento establecido en el art. 775 LEC. De acuerdo a este precepto, cuando el conflicto se dilucide al margen de los casos de violencia contra la mujer, la demanda de modificación de medidas se interpondrá ante el juzgado que dictó las medidas definitivas cuya modificación se pretende. Sin embargo, existían resoluciones contradictorias entre las distintas Audiencias Provinciales, sobre quién es el órgano competente para la modificación de medidas posterior a la sentencia de divorcio dictada por un juzgado de violencia sobre la mujer y cuando ha habido sobreseimiento de las actuaciones penales. El TS, en Auto del Pleno de la Sala de 14 de junio de 2017, ${ }^{39}$ sienta jurisprudencia y deja zanjada la cuestión al establecer que será competente el juzgado de primera instancia con competencia en materia de familia.

\footnotetext{
${ }^{39}$ Vid. Auto del Pleno de la Sala de 14 de junio de 2017. Conflicto de competencia 61/2017. Ponente: Francisco J. Arroyo Fiestas.
} 


\section{Perspectivas de futuro: Más allá de la prohibición de la custodia ni individual, ni compartida, la suspensión del régimen de visitas y la privación de la patria potestad}

Como apuntábamos más arriba, a propósito de la suspensión del derecho del régimen de estancia, relación y comunicación (derecho de visitas), la cuestión se presenta más controvertida. El art. 92.7 C.c. no se pronuncia al respecto, ${ }^{40}$ solo señala que "no procederá la custodia conjunta". Pero como se ha dicho, el art. 95 bis 5 del Anteproyecto va más allá y señala que no se atribuirá la guarda y custodia, ni individual ni compartida, ni un régimen de estancia, relación y comunicación respecto de los hijos e hijas, al progenitor que haya sido condenado penalmente por sentencia firme hasta la extinción de la responsabilidad penal. Previsión acertada, pero que tampoco debe ser aplicada con el automatismo y rigidez que señala la norma proyectada. ${ }^{41}$ Esta medida, absolutamente restrictiva, habrá de adoptarse con cautela, valorarla caso por caso, ponderando las circunstancias concurrentes hasta adoptar la decisión que más favorezca y garantice al niño y a la niña superar la traumática experiencia previa vivida; a la par que también coadyuvará a prevenir el riesgo de transferencia generacional del maltrato; aspecto trascendental al que alude reiteradamente la normativa protectora de la infancia y adolescencia. Fenómeno que preocupa, y mucho, cuando a la fecha actual conocemos la reproducción de esas conductas violentas a edades cada vez más tempranas.

El proyectado art. 95 bis 5 matiza, e incluye una excepción que queda a la discrecionalidad del juzgador: "excepcionalmente, el Juez podrá establecer, si lo considera conveniente para la protección del interés superior de los menores, atendiendo a los criterios anteriores y a la peligrosidad del progenitor condenado, un régimen de

\footnotetext{
${ }^{40} \mathrm{Si}$ bien el art. 94 C.c. regulador del derecho de visitas respecto del progenitor que no tenga consigo a sus hijos menores, establece, que dicho derecho podrá limitarse o suspenderse si se diesen graves circunstancias que así lo aconsejen o se incumplieren grave o reiteradamente los deberes impuestos en resolución judicial, subordinándose al interés y beneficio del menor, que ha de prevalecer sobre cualquier otro que pudiese concurrir.

${ }^{41}$ En parecido sentido se muestra la doctrina más reciente. Para Múrtula la Fuente (2016: 191 y ss), una medida tan drástica no se puede imponer al juzgador como regla general, porque no todos los casos de violencia de género son iguales. Guilarte Martín Calero (2008: 95-96) apunta que esta determinación no debe ser automática en aplicación de una indicación del legislador, sino consecuencia de una valoracion judicial. Pérez Conesa (2016: 79) apunta con acierto que ante la más mínima duda de existencia de violencia de cualquier índole, los casos deben ser examinados en profundidad por profesionales (...) La autora incide en un diagnóstico preventivo.
} 
estancia, relación y comunicación respecto de ellos". Y es en este punto donde el sistema falla a la hora de analizar el nivel de peligro actual y potencial al que puede exponerse el o la menor. Como ha quedado expuesto, puede existir riesgo cierto de que los niños y niñas se instrumentalicen para seguir ejerciendo maltrato sobre la mujer y riesgo de maltrato posterior al menor. ${ }^{42}$ En casos extremos, hasta llevarlos a la muerte, como el último y fatal episodio de violencia sobre la mujer.

Llegados a este punto, se nos hace difícil no traer a colación y reflexionar sobre los casos que tristemente conocemos a golpe de trágico titular. Hablamos de los asesinatos de niños y niñas a manos de su progenitor maltratador, aprovechando las estancias o régimen de visitas, con el único fin de provocar el mayor dolor que puede infligirse a una mujer. No cabe duda, que el acto homicida constituye el final de los episodios de maltrato hacia la madre. En los cinco primeros meses de 2017, ya son cinco los fallecidos; el último, al cierre de estas líneas. ${ }^{43}$ Lo que desde luego nos permite cuestionar y poner en tela de juicio la eficacia normativa de las últimas reformas acometidas en materia de protección a la infancia y adolescencia, y que dejamos a consideración del lector.

En este contexto, hay que recordar las advertencias que hizo la Resolución CEDAW 47/12 de 16 de julio de 2014 (Caso Ángela González Carreño contra España). ${ }^{44}$ Los hechos de que trae causa este asunto, son el asesinato de una niña a manos de su padre mediando régimen de visitas, pese a existir denuncias por violencia sobre la mujer. La Resolución, tras analizar el caso, estima la pretensión presentada por Ángela y entiende que España vulneró los arts. 2, 5 y 16 de la Convención sobre eliminación de toda forma de discriminación contra la mujer a través de las actuaciones judiciales,

\footnotetext{
${ }^{42}$ En este sentido se apunta que "En ocasiones, los padres pueden seguir maltratando a sus hijos después de la separación y utilizando al niño o la niña, de manera que siguen viviendo situaciones de violencia" (Save the Children 2011: 37).

${ }^{43}$ El menor de 11 años de edad, había pasado el fin de semana con su padre y debía entregarlo a su ex pareja, de quién llevaba varios años separado. La madre había presentado dos denuncias contra él en el pasado, la primera en el año 2008, por la que él acabó condenado por un delito de coacciones. Tuvo vigente una orden de alejamiento hasta 2013 y aquel año presentó una segunda denuncia por amenazas a través de las redes sociales, si bien finalmente fue sobreseída al no ser posible acreditar quién fue el autor de los hechos denunciados (El Mundo, 9 de mayo de 2017).

${ }^{44}$ Vid. Resolución CEDAW 47/12 de 16 de julio de 2014, del Comité para la eliminación de la discriminación contra la mujer (ONU) en aplicación de la Convención sobre la eliminación de todas las formas de discriminación contra la mujer.
} 
policiales, del Ministerio fiscal y administrativas habidas en los momentos previos a la muerte de su hija. El Comité considera que "las autoridades del Estado, al decidir el establecimiento de un régimen de visitas no vigilado aplicaron nociones estereotipadas $y$, por lo tanto, discriminatorias en un contexto de violencia doméstica, y fallaron en su obligación de ejercer la debida vigilancia”. Pero lo más importante es que recomienda a España "tomar medidas adecuadas y efectivas para que los antecedentes de violencia doméstica sean tenidos en cuenta en el momento de estipular los derechos de custodia y visita relativos a los hijos, y para que el ejercicio de los derechos de visita o custodia no ponga en peligro la seguridad de las víctimas de la violencia, incluidos los hijos. El interés superior del niño y el derecho del niño a ser escuchado deberán prevalecer en todas las decisiones que se tomen en la materia".

A nuestro modo, la Resolución CEDAW 47/12 ha supuesto un punto de inflexión en la materia que nos ocupa; y junto a la normativa protectora de la infancia y adolescencia, empieza a vislumbrarse un cambio en la jurisprudencia del Tribunal Supremo:

- En cuanto a la suspensión del derecho de visitas, ha sido significativa la STS de 26 de noviembre de $2015 .{ }^{45}$ La cuestión jurídica esencial que se planteó a través del recurso de casación, fue la posibilidad de que el progenitor condenado por delito de maltrato sobre su ex cónyuge y una de sus hijas, pudiera desarrollar un régimen de visitas en relación con otro de los hijos menores. El Juzgado de Primera Instancia optó por su establecimiento a favor del padre, si bien - en atención a las circunstancias concurrentes- dicho régimen de visitas debía llevarse a cabo cuando el padre saliera de la cárcel, tener un carácter restrictivo y a desarrollar en el Punto de Encuentro Familiar de forma tutelada. Además condicionado a que el progenitor justificara documentalmente, haberse sometido a un programa terapéutico para tratar su carácter violento, que le había llevado a cometer los hechos por los que había sido condenado. La Audiencia Provincial confirmó dicho pronunciamiento. El TS valorando los riesgos a los que se expone la menor, suspende el régimen de visitas y declara, sin margen de duda, que "la

\footnotetext{
${ }^{45}$ STS núm. sentencia 680/2015 de 26 de noviembre (RJ 2015/5624)
} 
sentencia recurrida no respeta el interés de la menor, al no concretarse los aspectos que debe contener el programa terapéutico que establece, ni ante quién lo debe desarrollar, ni quién homologará los resultados obtenidos, por lo que de acuerdo con el art. 94 del C. Civil y art. 65 de la Ley Orgánica 1/2004 no ha lugar a fijar régimen de visitas". Alude a la LO 8/2015 y a la concreción normativa que introduce con respecto al "interés superior de los y las menores"; en tanto en cuanto cualquier decisión que les afecte deberá ir encaminada a proteger la satisfacción de sus necesidades básicas (materiales, físicas, educativas, emocionales, afectivas, etc.), garantizar la estabilidad de las soluciones que se adopten, a que las medidas que se adopten no restrinjan o limiten más derechos que los que amparan y a garantizar un entorno libre de violencia”. Acertadamente señala que "los contactos de un padre con su hija, cuando aquel previamente ha sido condenado por malos tratos a otra de sus hijas, deben ser sumamente restrictivos y debe predominar la cautela del tribunal a la hora de fijarlos, pues el factor de riesgo es más que evidente, en relación con un menor con escasas posibilidades de defensa." 46

- En cuanto a la privación de la patria potestad en vía penal y para evitar dilaciones que siempre son perjudiciales, cabe mencionar dos sentencias del TS. La primera la STS de 30 de septiembre de $2015^{47}$ que priva de la patria potestad a un padre que intentó asesinar a su pareja en presencia de la hija de ambos. Lo relevante de este pronunciamiento está en que la Sala de lo Penal del TS ha sido reacia a la adopción de la privación de la patria potestad, sin perjuicio de que fuera en la vía civil donde se acordara la medida. Pues a pesar de estar prevista con carácter potestativo en el art. $55 \mathrm{CP}$ en penas de prisión igual o superior a diez años, ${ }^{48}$ la

\footnotetext{
${ }^{46}$ Con respecto a este último criterio el TS cita expresamente el art. 2 de la LO 8/2015 por cuanto señala que "en caso de que no puedan respetarse todos los intereses legítimos concurrentes, deberá primar el interés superior del menor sobre cualquier otro interés legítimo que pudiera concurrir".

47 Vid. STS (Sala de lo penal) 30 de septiembre de 2015. Número de sentencia 568/2015Id. Cendoj: 28079120012015100558 Ponente: Joaquín Giménez García.

${ }^{48} \mathrm{El}$ art. $55 \mathrm{CP}$ prevé que "La pena de prisión igual o superior a diez años llevará consigo la inhabilitación absoluta (...) El Juez podrá además disponer la inhabilitación especial para el ejercicio de la patria potestad, tutela, curatela, guarda o acogimiento, o bien la privación de la patria potestad, cuando estos derechos
} 
aplicación del precepto exige una vinculación o "relación directa" entre el delito y la privación de este derecho. Relación directa que, hasta ahora, se estimaba ausente cuando el delito cometido no tenía como destinatarios directos a los hijos e hijas, aunque hubiesen presenciado los hechos. De hecho la SAP de Guadalajara, de 23 de Enero de 2015, recurrida en casación, estimó que la pena de privación de la patria potestad no procede de forma automática. Para la Audiencia, "no basta pretender su imposición por el mero reproche objetivo de la conducta cometida por el acusado", sino que debe acreditarse que los hechos son perjudiciales para el menor. Prueba ésta que, para la Audiencia, "no había acontecido", estimando que tampoco existe una vinculación entre el delito y la privación de este derecho. Pero el TS no comparte esta argumentación y señala como dato incontestable, que la presencia de la menor en el ataque a su madre efectuado por su padre, va a tener un prolongado efecto negativo en su desarrollo en el caso de mantener la patria potestad. La Sala precisa que la patria potestad se integra, ex art. $154 \mathrm{CC}$ por una serie de deberes de los padres para sus hijos e hijas menores, por lo que se trata de una institución tendente a velar por su interés. Por lo que "Repugna legal y moralmente mantener al padre en la titularidad de unas funciones respecto de las que se ha mostrado indigno; pues resulta difícil imaginar un más grave incumplimiento de los deberes inherentes a la patria potestad que el menor presencie el severo intento del padre de asesinar a su madre". Línea jurisprudencial que se consolida en la reciente STS de 14 de junio de $2017 .{ }^{49}$ En el caso de autos, se priva de la patria potestad al padre de los tres menores por existir una relación directa entre el delito cometido contra la madre (asesinato) y la relación paterno filial. Por lo que se acuerda tal privación en el propio proceso penal para evitar dilaciones que "si siempre son perjudiciales, en casos como el presente, pueden ocasionar un daño irreparable en el desarrollo del hijo menor". Más aún cuando los hechos se cometieron en el domicilio familiar y que durante su comisión se hallaba presente en él la hija menor, que resultó manchada con la

hubieren tenido relación directa con el delito cometido. Esta vinculación deberá determinarse expresamente en la sentencia."

${ }^{49}$ Vid. STS (Sala Segunda) de 14 de junio de 2017 Número Sentencia: 432/2017 Número Recurso: 10022/2017 Ponente: Andrés Palomo del Arco 
sangre de su madre. El TS califica "ataque frontal” contra la integridad moral de estos menores, privados de tan abrupta y cruel manera de un progenitor, con obvio perjuicio para el equilibrado y armónico desarrollo de su personalidad. Ataque que expresamente reconoce "resultaría potenciado y agravado con el mantenimiento de la patria potestad en el padre". 50

Puede colegirse que esta nueva línea jurisprudencial prioriza y aplica debidamente el principio del "interés del menor". En línea con las modificaciones legislativas de protección a la infancia y adolescencia, valora explícitamente la situación de riesgo a la que se expone el o la menor y otorga prevalencia a los derechos de los hijos e hijas, victimas directas de esa violencia extendida, frente a los derechos derivados de relación paterno filial.

\section{Reflexiones finales}

Tras la crisis o ruptura afectiva de la pareja, no cabe duda que el interés del menor aconseja seguir manteniendo contacto con ambos progenitores y la custodia compartida sería la mejor manera de protegerlo. Pero no siempre es posible, especialmente cuando el contexto familiar revela con evidencias explícitas que el o la menor ha vivido expuesto a episodios repetidos de actos de violencia ejercida por el padre hacia la madre. El art. 92.7 C.c. se presenta como una garantía para su no otorgamiento, pero su aplicación práctica no ha estado exenta de contradicciones, en gran medida, por su redacción confusa e incompleta, no aplicando la prohibición expresa y estableciendo la custodia conjunta, si se estima que de esta forma queda salvaguardado el superior interés del menor.

Las últimas modificaciones legislativas han incorporado previsiones expresas de gran impacto en la materia cuando la crisis familiar o de pareja se anuda en situaciones

\footnotetext{
${ }^{50}$ La Sala considera que la acción ejecutada colisiona frontalmente con el deber paterno de procurar una formación integral a los hijos y que resulta contraproducente que el condenado siga ostentando la representación procesal de los menores con quienes mantiene "una manifiesta contraposición de intereses" por razón de su obligación de indemnizarles a causa de la muerte de su madre
} 
de violencia de género. Entre ellas, las leyes de modificación del sistema de protección a la infancia y a la adolescencia (LO 8/2015, de 22 de julio y la Ley 26/2015, de 28 de julio) y la Ley 4/2015, de 27 de abril, del Estatuto de la Víctima del Delito. Sin duda, la de mayor calado es el reconocimiento expreso de "víctimas directas" de dicha violencia a los hijos e hijas. Por fin se visibiliza que los menores que viven expuestos a la violencia de género sufren maltrato infantil como modalidad específica de violencia de género y son víctimas directas de este maltrato. Lo que repercute en las medidas civiles de orden personal que les afectan y para cuya adopción, la concreción del "interés del menor" ha quedado claramente establecida.

No admite matices que los antecedentes de violencia doméstica y de género concretan esa difícil noción del "interés del menor". Pues estos niños y niñas, a pesar de no haber recibido agresión directa, no han sido preservados y sufren las consecuencias de una atroz violencia extendida, con los riesgos inherentes a tal consideración. Incluso más allá de las secuelas psicológicas que presentan por las experiencias previas vividas, pueden convertirse en instrumento para seguir ejerciendo control y maltrato hacia la mujer, con directa repercusión en ellos y ellas. Circunstancias que, sin paliativos, necesariamente deben ser atendidas en el momento de acordar o modificar el régimen de guarda y custodia y de relación de hijos e hijas con el progenitor maltratador. Así lo refrenda la nueva línea jurisprudencial que prioriza y aplica debidamente el principio del “interés del menor" y otorga prevalencia a sus derechos, frente a los derechos derivados de relación paterno filial. Se supera progresivamente la resistencia a la retirada de la guarda y custodia, privación de la patria potestad y suspensión del régimen de relación con el progenitor maltratador.

En esta línea, más allá de la custodia compartida proscrita en el art. 92.7 C.c., las perspectivas de futuro apuntan en esta dirección restrictiva de derechos. El art. 95 bis 5 del Anteproyecto de Ley sobre el ejercicio de la corresponsabilidad parental, si bien no vio la luz en la pasada legislatura, nos sirve como parámetro a considerar para una futura e inminente regulación. El proyectado precepto, con una redacción más ajustada, introduce una modificación importante en este punto, y que a fecha de hoy recobra especial interés. Extiende la prohibición, no solo a la custodia individual y a la 
compartida; sino también al régimen de estancia, relación y comunicación (derecho de visitas). Previsiones para las que al parecer existe consenso, tras el acuerdo político alcanzado para la aprobación del Pacto de Estado contra la Violencia de Género.

Pero ciertamente, la materia que nos ocupa, no admite respuestas absolutas predispuestas en un frio precepto legal. El fundamento del vigente art. 92.7 C.c., del proyectado 95 bis 5, así como la normativa conexa citada y la que está por venir, tienen un hilo conductor común; y es que, en la ordenación de la custodia, individual o compartida, y el derecho de estancia, relación, y comunicación del progenitor violento con los hijos e hijas, debe primar el principio de preservar al menor de una situación objetiva de peligro o riesgo. Y es aquí donde el sistema falla y nos permite cuestionar la eficacia, suficiencia e implementación de las medidas para proteger a los y las menores, víctimas de la violencia machista. En ocasiones, el factor de riesgo es difícil o tardíamente identificado, con resultados drásticos que conocemos a golpe de trágico titular. En otros casos, aún contando con mecanismos e instrumentos para actuar ante evidencias explícitas de maltrato, persisten obstáculos de índole jurídico, reticencias de índole institucional y falta de medios, que abocan en decisiones cuestionables sobre la custodia y régimen de relación de hijos e hijas con el progenitor maltratador. Lo que supone sin duda, una victimización secundaria que afecta a madres, hijos e hijas; y lo que es peor, ponen en riesgo su integridad física, moral y emocional.

Por lo que se hace preciso reforzar las medidas que en fase de prevención ya están previstas, con coordinación de los distintos agentes implicados; así como la implementación de Protocolos que puedan evaluar fielmente la situación de riesgo a la que se expone el o la menor. Y en caso de que no puede garantizarse que la vida de niños, niñas y adolescentes se desarrolle en un entorno seguro y libre de violencia, no establecer contactos con el progenitor; o en su caso, si el interés del menor lo aconseja, ponderando todas las circunstancias, ser sumamente restrictivos, con la debida cautela y sensibilización por parte del tribunal a la hora de fijarlos. Contactos que necesariamente requieren ser supervisados y con seguimiento periódico de su evolución. Lo que es obstáculo, sino una garantía para una futura revisión de la medida. No se trata de estigmatizar al progenitor que ha sido violento, pero como ha quedado expuesto, el 
legislador concreta el interés del menor que, en todos los procedimientos relacionados con la violencia de género, queda claramente definido, ante esta grave violación del derecho a la vida, a la integridad y a vivir en un entorno familiar libre de violencia.

\section{Referencias bibliográficas}

Acuña San Martín, Marcela. 2014. Derecho de relación entre los hijos y el progenitor no custodio tras el divorcio. Madrid: Dykinson.

Atenciano Jiménez, Beatriz. 2009. "Menores expuestos a violencia contra la pareja: notas para una práctica clínica basada en la evidencia”. Clínica y Salud, vol. $20 \mathrm{n}^{\mathrm{o}} 3$. 2009: 261-272.

Bodelón, Encarna. 2014. "Violencia institucional y violencia de género". Anales de la Cátedra Francisco Suárez, vol. 48 (2014), 131-155.

Circular FGE 6/2011, de 2 de noviembre, sobre criterios para la unidad de actuación especializa del Ministerio Fiscal en relación con la violencia sobre la mujer. (LA LEY 1772/2011).

Comité de los Derechos del Niño. 2013. “Observación general n¹4”.

García Rubio, M. Paz y Otero Crespo, Marta. 2006. “Apuntes sobre la referencia expresa al ejercicio compartido de la guarda y custodia de los hijos en la ley 15/2005". Revista Jurídica de Castilla y León, $\mathrm{n}^{\mathrm{o}} 8$ (febrero 2006).

Guía practica de la Ley Orgánica 1/2004, de 28 de diciembre, de Medidas de Protección Integral contra la Violencia de Género. CGPJ (2016).

Guilarte Martín-Calero, Cristina. 2008. "La custodia compartida alternativa. Un estudio doctrinal y jurisprudencial”. InDret 2/2008.

Guilarte Martín-Calero, Cristina. 2014. La concrecion del interés del menor en la jurisprudencia del Tribunal Supremo. Valencia: Tirant lo Blanch. Colección Privado $n^{\circ} 107$.

González del Pozo, Juan P. y Campo Izquierdo, Ángel L. 2016. “La presión social e intereses asociativos impiden la aprobación de una ley de guarda y custodia compartida". Diario La Ley núm. 8701, 12 de febrero de 2016.

Memoria de la Fiscalía General del Estado de fecha 6 de septiembre de 2016. Fiscal de Sala Coordinadora contra la Violencia sobre la Mujer. http://observatorioviolencia.org/de-las-casi-130-000-denuncias-por-violencia-degenero-registradas-en-2015-solo-dos-fueron-falsas/ [6 septiembre 2016]. 
Múrtula la Fuente, Virginia. 2016. El interés superior del menor y las medidas civiles a adoptar en supuestos de violencia de género. Madrid: Dykinson.

Observatorio de Violencia Doméstica y de Género del CGPJ. Nota de prensa CGPJ de 29 junio 2016

Ordóñez Fernández, Ma del Prado. y González Sánchez, Patricio. 2012. "Las víctimas invisibles de la Violencia de Género". Revista Clínica de Medicina de Familia, vol. $5, \mathrm{n}^{\mathrm{o}} .1: 30-36$.

Pérez Conesa, Carmen. 2016. La Custodia compartida. Cizur, Navarra: Aranzadi.

Reyes Cano, Paula. 2015. "Menores y violencia de género: de invisibles a visibles". Anales de la Cátedra Francisco Suárez, vol. 49 (2015): 181-217.

Ruiz de la Cuesta Fernández, Soledad. 2013. "La atribución de la custodia compartida en supuestos de violencia intrafamiliar". Práctica de Tribunales (Revista especializada en Derecho procesal civil y mercantil). Año 10, enero 2013: 100-112.

Save the Children. 2011. En la violencia de género no hay una sola víctima. Atención a los hijos e hijas de mujeres víctimas de violencia de género. https://www.savethechildren.es/sites/default/files/imce/docs/violencia_de_genero _victima.pdf. [5 enero 2012]

Sepúlveda García de la Torre, Ángeles. 2006. "La violencia de género como causa de maltrato infantil". Cuadernos de Medicina Forense, vol. 12, no 43-44 (enero-abril 2006): 149-164.

Ureña Carrazo, Belén. 2016. "La conflictividad entre los progenitores como criterio de atribución de la custodia compartida". La Ley Derecho de Familia. Revista jurídica sobre Familia y Menores, no 11 (2016).

Villagrasa, Carlos. 2015. "Derechos de la infancia y la adolescencia: hacia un sistema legal”. Anales de la Cátedra Francisco Suárez, vol. 49 (2015): 17-41. 